\title{
Renal injury is accelerated by global hypoxia-inducible factor 1 alpha deficiency in a mouse model of STZ-induced diabetes
}

\author{
Romana Bohuslavova ${ }^{1}$, Radka Cerychova ${ }^{1,2}$, Katerina Nepomucka $^{1}$ and Gabriela Pavlinkova ${ }^{1 *}$
}

\begin{abstract}
Background: Hypoxia inducible factor 1 (HIF-1) activates protective pathways to counteract hypoxia and prevent tissue damage in conjunction with renal injury. The aim of this study was to evaluate a role of HIF-1 in diabetes-induced kidney damage.

Methods: We used a streptozotocin-induced diabetes mouse model and compared biochemical, histological and molecular parameters associated with kidney damage in Hifla deficient ( $\left.\mathrm{Hifla}^{+/}\right)$and wild-type mice.

Results: We showed that Hifla deficiency accelerated pathological changes in the early stage of DN. Six weeks after diabetes-induction, Hifla deficient mice showed more prominent changes in biochemical serum parameters associated with glomerular injury, increased expression of podocyte damage markers, and loss of podocytes compared to wild-type mice. These results indicate that Hifla deficiency specifically affects podocyte survival in the early phase of DN, resulting in diabetic glomerular injury. In contrast, renal fibrosis was not affected by the global reduction of Hifla, at least not in the early phase of diabetic exposure.

Conclusions: Together our data reveal that HIF-1 has an essential role in the early response to prevent diabetes-induced tissue damage and that impaired HIF-1 signaling results in a faster progression of DN. Although the modulation of HIF-1 activity is a high-priority target for clinical treatments, further study is required to investigate HIF-1 as a potential therapeutic target for the treatment of DN.
\end{abstract}

Keywords: Diabetic complications, Diabetic nephropathy, Hypoxia, Podocyte, Mouse model

\section{Background}

Diabetic nephropathy (DN) is an endemic complication of diabetes and the leading cause of end-stage renal failure. Clinical features of DN are progressive albuminuria, proteinuria, and an eventual reduction in the glomerular filtration rate [1]. The complex progressive histopathological changes associated with DN include mesangial matrix expansion, thickening of basement membranes, glomerular and tubular hypertrophy, podocyte loss, and glomerulosclerosis and tubulointerstitial fibrosis [2]. High glucose is a primary initiating factor of multiple molecular,

\footnotetext{
* Correspondence: gpavlinkova@ibt.cas.cz

'Laboratory of Molecular Pathogenetics, Institute of Biotechnology CAS, BIOCEV, Center of Excellence, Prumyslova 595, Vestec 25242, Czechia

Full list of author information is available at the end of the article
}

metabolic, and hemodynamic changes resulting in kidney damage, including intrarenal tissue hypoxia [3]. Tissue hypoxia activates multiple pathways, such as profibrotic growth factors, hemodynamic cytokines (angiotensin II), advanced glycation end products (AGE), and reactive oxygen species (ROS). Thus, both hyperglycemia and hypoxia are major determinators of the chronic complications associated with diabetes.

A master regulator of transcriptional responses to hypoxia is hypoxia inducible factor 1 (HIF-1). HIF-1 has been recently associated with the progression of chronic renal injuries including DN [4-6]. HIF-1 consists of two subunits, HIF- $1 \alpha$, an $\mathrm{O}_{2}$-labile subunit, and constitutively expressed HIF-1 $\beta$ [7]. Hifl $\alpha^{+/-}$heterozygote mutants demonstrate impaired responses when challenged with hypoxic conditions after birth [8, 9]. HIF-1 directly regulates the expression of more than 1000 human genes 
(for review, see [10]). Although the expression of a subset of HIF-1 target genes is induced by hypoxia in most or all cell types, the majority of these genes are induced by hypoxia in a cell type-specific manner. In addition to hypoxia, the HIF- $1 \alpha$ subunit activity is regulated by numerous other factors, including growth factors, cytokines, sirtuins, ROS, and intracellular metabolites, even under normoxic conditions [11]. However, the mechanism of HIF-1 $\alpha$ stabilization in a hyperglycemic environment is controversial. Hyperglycemia upregulates HIF- $1 \alpha$ in the glomeruli of diabetic model mice regardless of the etiology of the diabetes $[5,12]$. The activation of HIF-1 in the diabetic kidney may be suboptimal despite profound renal hypoxia, as suggested by a large body of evidence showing that the diabetic milieu deregulates the HIF-1 $\alpha$ pathway [13-15]. It remains controversial whether the activation of HIF-1 signaling exerts a beneficial or harmful role in the progression of renal diseases, particularly DN. An indirect approach using YC-1 [3-(5'-hydroxymethyl-2'-furyl)1-benzyl indazole], a HIF-1 inhibitor, reduced glomerular hypertrophy and AGE-tissue modifications in the type 1 diabetes mouse model [6]. In contrast, an activation of HIF- $1 \alpha$ by $\mathrm{CoCl}_{2}$ reduced proteinuria and histological markers of kidney injury in an obese type 2 diabetes model [16] and in STZ-induced DN in rats [3].

To provide more insight into the functional role of HIF- $1 \alpha$ pathways, we examine the relationship between diabetes-induced kidney injury and the partial deficiency of HIF- $1 \alpha$ caused by the global deletion of the Hifl $\alpha$ functional allele with a specific focus on the early phase of diabetes-exposure. Together, our data suggest the potential roles of HIF- $1 \alpha$ and Hifl $\alpha$ genetic variations in the manifestation of DN. Furthermore, our data point out the necessity of optimizing any possible pharmacological inhibition of HIF-1 in therapeutic applications of $\mathrm{DN}$ and diabetes-associated pathologies.

\section{Methods}

\section{Experimental animals}

This study was conducted in accordance with the Guide for the Care and Use of Laboratory Animals (NIH Publication No. 85-23, revised 1996). The experimental protocol was approved by the Animal Care and Use Committee of the Institute of Molecular Genetics, CAS. Diabetes was induced in male inbred FVB ( $\mathrm{Wt}$, strain code 207, Charles River) and Hifl ${ }^{+/-}$strain on the FVB background, aged 7-9 weeks, by 2 intraperitoneal injections of $100 \mathrm{mg} / \mathrm{kg}$ body weight of streptozotocin (STZ; Sigma, St. Louis, MO), as described $[17,18]$. Mice were sacrificed after 6 weeks of diabetes at age 15-17 weeks. The Hifl $\alpha$ mutants with the Hif1 ${ }^{\text {atm IJhu }}$ mutant allele [19] were obtained from Prof. Gregg L. Semenza. Hifla ${ }^{+/-}$ mice showed a partial loss of HIF- $1 \alpha$ protein expression levels $[20,21]$. The $H i f 1 \alpha^{+/-}$mouse colony was bred and maintained in our laboratory. Offspring of Wt $\mathrm{x} \mathrm{Hifl \alpha}^{+/-}$ matings were genotyped by PCR [22], using DNA isolated from tails and amplifying neomycin (Neo) and Hifla exon 2 sequences [19]; Neo (463-bp) and Hifl $\alpha$ (317-bp).

\section{Biochemical parameters}

Blood serum was collected following a 6-h fast (from 7 a.m. to 1 p.m. as recommended by the $\mathrm{NIH}$ for mouse metabolic models [23]) and was analyzed using a Beckman Coulter AU480 Chemistry Analyzer (Beckman) according to the manufacturer's protocol in the Core Facility of Czech Centre for Phenogenomics in Biocev.

\section{Real-time reverse-transcription PCR (RT-qPCR)}

Total RNA was isolated from the renal cortex of diabetic $W t$, non-diabetic and diabetic Hifla $\alpha^{+/-}(\mathrm{EXP})$, and from non-diabetic $W t$ (control); the renal medulla was discarded. Following RT, quantitative real-time PCR (qPCR) was performed as described [9]. The relative expression of a target gene was calculated, based on qPCR efficiencies $(\mathrm{E})$ and the quantification cycle $(\mathrm{Cq})$ difference $(\Delta)$ of an experimental sample versus control $\left(\right.$ ratio $=\left(E_{\text {target }}\right)^{\Delta \mathrm{Cq}}$ Hif1a $($ Mean control - Mean EXP)/ $\left(E_{\mathrm{Hprt1}}\right)^{\Delta \mathrm{Cq} \text { Hprt1(Mean control - Mean EXP) }}$. RT-qPCR data were analyzed using the GenEX5 program (www.multid.se/genex/genex.html). Primer sequences are presented in Additional file 1: Table S1.

\section{Western blot}

The renal cortexices from the diabetic and non-diabetic kidneys were lysed with protease and phosphatase inhibitors to prevent protein degradation and stored at $-80{ }^{\circ} \mathrm{C}$ until analysis. Fifty microgram of total protein lysates were denatured, resolved using 10\% SDS-PAGE, and transferred to a nitrocellulose membrane, as described in detail previously [18]. The membrane was blocked with $5 \%$ dry milk and incubated overnight with rabbit antiCX43 antibody at 1:6000 (\#C6219, Sigma), or anti-VEGFA at 1:200 (\#sc-7269; Santa Cruz Biotechnology, TX, USA). After incubation with a horseradish peroxidase-conjugated secondary IgG (Sigma), the blots were developed using the SuperSignal ${ }^{\text {Tw }}$ West Femto Maximum Sensitivity Substrate (\#34095; Thermo Scientific, MI, USA). Chemiluminescent signals were captured using an ImageQuant LAS 4000 Imager (GE Healthcare Bio-Sciences AB, Sweden) and analyzed by ImageJ software (http://imagej.nih.gov/ij/download.html). Ponceau S staining was used as the loading control.

\section{Histology and immunohistochemistry}

To detect tissue modifications and tissue remodeling we used the Periodic acid-Schiff (PAS) staining system 
(\#395B, Sigma, St. Louis, MO) and Trichrome Stain (Masson) Kit (\#HT15-1KT, Sigma), respectively. Paraffin sections $(8 \mu \mathrm{m})$ were dehydrated and used for the both methods. PAS $^{+}$area was delineated using the Adobe Photoshop CS5.1 program. Quantification of the PAS and collagen positive areas was performed using the threshold tool in the ImageJ program (http://imagej.nih.gov/ij/download.html), separating pixels which fall within a desired range of intensity values from those which do not.

Sections $(8 \mu \mathrm{m})$ for immunohistochemistry were heated in citrate buffer $(0.07 \mathrm{M}, \mathrm{pH}$ 6.0) for antigen retrieval and blocked with PBS (pH 7.4) with 0.1\% Tween 20 (\#P9416, Sigma) and 10\% normal goat serum (\#005-000-121, Jackson Immuno Research Labs). Primary antibodies used: mouse anti-VEGFA 1:50 (\#sc-7269, Santa Cruz Biotechnology), rabbit anti-pHH3 1:100 (\#06-570, Merck Millipore), rabbit anti-WT1 1:200 (\#CA1026, Merck Millipore) and mouse anti-alpha smooth muscle actin ( $\alpha$-SMA) 1:400 (\#A2547, Sigma). Secondary antibodies used: Alexa Fluor 488 and 594 1:400 (\#115-545-146 and \#111-585-144, resp., Jackson Immuno Research Labs). The sections were counterstained with Hoechst 33,342 (\#14533 Sigma) and imaging with confocal microscope (ZEISS LSM 880 NLO). The areas of VEGFA and $\alpha$-SMA expression, and a number of $\mathrm{WT}^{+}$ podocytes and $\mathrm{pHH}^{+}$nuclei in the renal cortex were quantified using the ImageJ.

\section{Statistics}

All values are means \pm SEM. We used two-way ANOVA to compare differences among experimental groups with genotype and experimental condition (diabetes or no diabetes) as categories. When a significant interaction was detected, the differences between subgroups were further analyzed by post hoc Tukey's multiple comparison tests; significance assigned at the $P<0.05$ level (Graph Pad, 2005; Graph Pad, San Diego, CA).

\section{Results \\ Changes in physiological and biochemical parameters after 6 weeks of diabetes}

For this study we used the well-established STZ-induced diabetes mouse model on the FVB genetic background $[17,18]$. Age-matched wild-type Hifl $\alpha^{+/+}(W t)$ and $\mathrm{Hifl}^{+/-}$mice were compared. Body weight gain after 6 weeks was significantly decreased in diabetic mice of both genotypes (Fig. 1a; non-diabetic Wt $6.3 \pm 0.6 \mathrm{~g}$ $(n=9)$, diabetic Wt $0.6 \pm 0.6 \mathrm{~g}(n=11)$, non-diabetic $H_{i f 1} \alpha^{+/-} 5.9 \pm 0.9 \mathrm{~g}(n=6)$ and diabetic Hiflo ${ }^{+/-}$ $1.3 \pm 0.7 \mathrm{~g}(n=12))$. In contrast, the kidney weight-tobody weight ratios were increased in diabetics compared to controls (Fig. 1b; non-diabetic Wt $0.009 \pm 0.0004 \mathrm{~g}$ $(n=17)$, diabetic $W t 0.014 \pm 0.001 \mathrm{~g}(n=8)$, nondiabetic Hifl $\alpha^{+/-} 0.010 \pm 0.001 \mathrm{~g}(n=6)$ and diabetic
Hif1 $\left.{ }^{+/-} 0.017 \pm 0.004 \mathrm{~g}(n=11)\right)$, consistent with diabetic renal hypertrophy phenotype $[4,24]$.

Increased serum levels of creatinine and phosphorus, and decreased serum levels of albumin are the first markers of kidney damage due to high glucose concentrations [4]. Blood serum was collected from non-diabetic and diabetic Wt and Hifl $\alpha^{+/-}$mice after $6 \mathrm{~h}$-fasting. Both $W t$ and $H i f 1 \alpha^{+/-}$mice developed high levels of hyperglycemia after STZ injections over the 6-week study (Fig. 1c). Interestingly, serum glucose levels were significantly higher in diabetic $\mathrm{Hifl}^{+/-}$compare to diabetic Wt mice. Serum phosphorus levels were also slightly higher in non-diabetic Hifl $\alpha^{+/-}$compared to non-diabetic Wt mice (Fig. 1c). As serum phosphorus is a cardiovascular risk factor [25], these data correspond with a predisposition of $\mathrm{Hifl}^{+/-}$mutation for endothelial dysfunction and cardiovascular disease $[8,9,18]$. Phosphorus and creatinine levels were significantly increased, whereas the levels of albumin were significantly reduced in diabetic $\mathrm{Hifl}^{+/-}$ compared to diabetic Wt mice (Fig. 1c).

\section{Tissue modification and remodeling in the renal cortex}

Periodic acid-Schiff (PAS) staining is a method for the detection of AGE, non-enzymatic tissue modifications [26]. A weak positive staining was detected in the tubular part of the renal cortex of non-diabetic Hifl $\alpha^{+/-}$mice (Fig. 2a, b), suggesting AGE modifications due to Hifl $\alpha$ deficiency even under normal conditions. A significantly higher production of AGE products was detected in both the diabetic Wt and Hifl $\alpha^{+/-}$renal cortex (Fig. 2e). Using Masson's trichrome staining, we analyzed interstitial collagen deposition in the renal cortex as an index of interstitial fibrosis and overall tissue remodeling (Fig. 2c, d). We did not detect any differences in collagen deposition between non-diabetic Wt and $\mathrm{Hifl}^{+/-}$. Collagen accumulation was significantly increased in both $W t$ and $\mathrm{Hifl}^{+/-}$diabetic groups, although the trend of more abundant tissue remodeling was evident in the diabetic $\mathrm{Hifl}^{+/-}$renal cortex (Fig. 2f). Based on light microscopy evaluation, we detected only mild mesangial expansion without nodular sclerosis (Fig. 2c, arrow), classified as class $\mathrm{I} / \mathrm{II} \mathrm{DN}$, which is a characteristic early stage of DN [27].

\section{Molecular changes in the renal cortex of diabetic mice with $\mathrm{Hifla}^{+/-}$deficiency}

This study assesses the effects of partial Hifl $\alpha^{+/-}$deficiency on the progression of DN in early stages of diabetes. We analyzed the expression of genes associated with extracellular matrix expansion, podocyte dysfunction, and profibrotic responses with a specific focus on HIF-1 $\alpha$ direct target genes (Fig. 3a). Hif1 $\alpha$ partial deficiency was demonstrated by a reduced expression of HIF-1-targeted genes (Pdk1, Ntn1, Ctgf, and Fn1) in the renal cortex under non-diabetic conditions. The mRNA level of adrenomedullin (Adm), a 

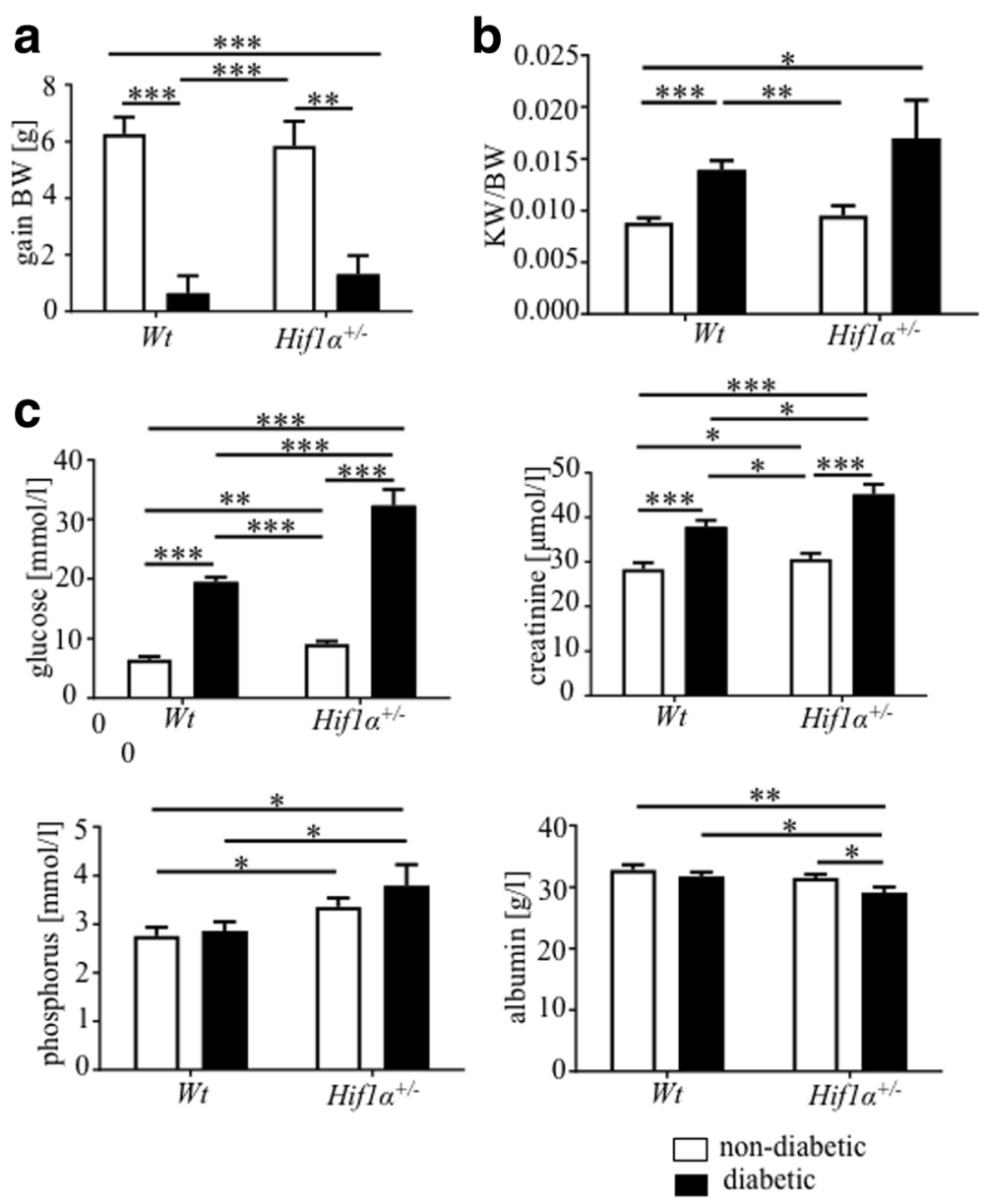

Fig. 1 Physiological and biochemical parameters. a Body weight gain after 6 weeks from the induction of diabetes. b Changes in kidney/body weight ratio (KW/BW) after 6 weeks of diabetes exposure. The values represent means \pm SEM (non-diabetic Wt $(n=9)$, diabetic Wt $(n=11)$, non-diabetic Hifla ${ }^{+-}(n=6)$ and diabetic Hifla $\left.a^{+-}(n=12)\right)$. Two-way ANOVA showed significant effect of diabetes in the body weight gain $(P<0.0001)$ and in the KW/BW $(P=0.0005)$. c The levels of glucose, creatinine, phosphorus, and albumin in the blood serum of $W t$ and $\mathrm{Hifl} \mathrm{a}^{+/-}$mice after $6 \mathrm{~h}$ fasting and collected at the end of experiment ( 6 weeks from the induction of diabetes). The values represent means \pm SEM ( $n=8$ mice in each group). Statistical significance assessed by two-way ANOVA: genotype effect (creatinine, $P<0.001$; phosphorus, $P=0.0037$; albumin, $P=0.027$ ); diabetes effect (creatinine, $P<0.0001$; albumin, $P=0.027$ ); and interaction between genotype and diabetes: glucose $P<0.0001$. ${ }^{*}$ Significant differences by post hoc pairwise comparison tests, ${ }^{*} P<0.05$, ${ }^{* *} P<0.01$, ${ }^{* * *} P<0.001$

potent vasodilatory peptide hormone, was increased in the diabetic $\mathrm{Hifl}^{+/-}$kidney cortex compared to other experimental groups. The relative gene expression of podocin (Nphs2), a marker for podocyte damage, was significantly elevated only in the diabetes-exposed $\mathrm{Hifl}^{+/-}$renal cortex. Collagen accumulation has been associated with the upregulation of the transcription factor Sox 9 , a direct HIF- $1 \alpha$ target [28]. A significant increase in the mRNA level of the Sox9 gene was detected in the diabetic $\mathrm{Hifl}^{+/-}$kidney cortex. A pivotal cytokine in the profibrotic responses [29], transforming growth factor beta $1(\operatorname{Tg} f \beta 1)$, was significantly increased in both diabetic groups (the effect of diabetes, $P<0.05$ by two-way ANOVA). Fibronectin (Fn1) and connective tissue growth factor (Ctgf), classical markers of fibrosis and indicators of extracellular matrix accumulation, were increased in diabetic mice (significant effect of diabetes $P<0.008$ and effect of genotype $P<0.01$ by twoway ANOVA). As HIF- $1 \alpha$ direct target genes, both $F n 1$ and Ctgf were significantly decreased in non-diabetic Hifla $\alpha^{+/-}$ mice, suggesting impaired HIF-1 $\alpha$ regulation. The partial deficiency of netrin-1 (Ntn1) results in kidney microvascular dysfunction and accelerated DN [30]. Correspondingly, the expression of $N t n 1$ was reduced in the diabetic $W t$ and Hifl $\alpha^{+/-}$renal cortex compared with non-diabetic Wt. We also found a significant reduction of Ntn1, a direct HIF- $1 \alpha$ target, in the non-diabetic Hifl $\alpha^{+/-}$compared to Wt mice, indicating altered HIF- $1 \alpha$ regulation. We found that the expression of Cx43 [31] in the renal cortex was significantly attenuated in non-diabetic $\mathrm{Hifl}^{+/-}$. Cx43 participates in intercellular communication and is down-regulated by diabetes [32]. Accordingly, in our experimental diabetic model, both diabetic groups Wt and Hifl $\alpha^{+/-}$showed decreased 

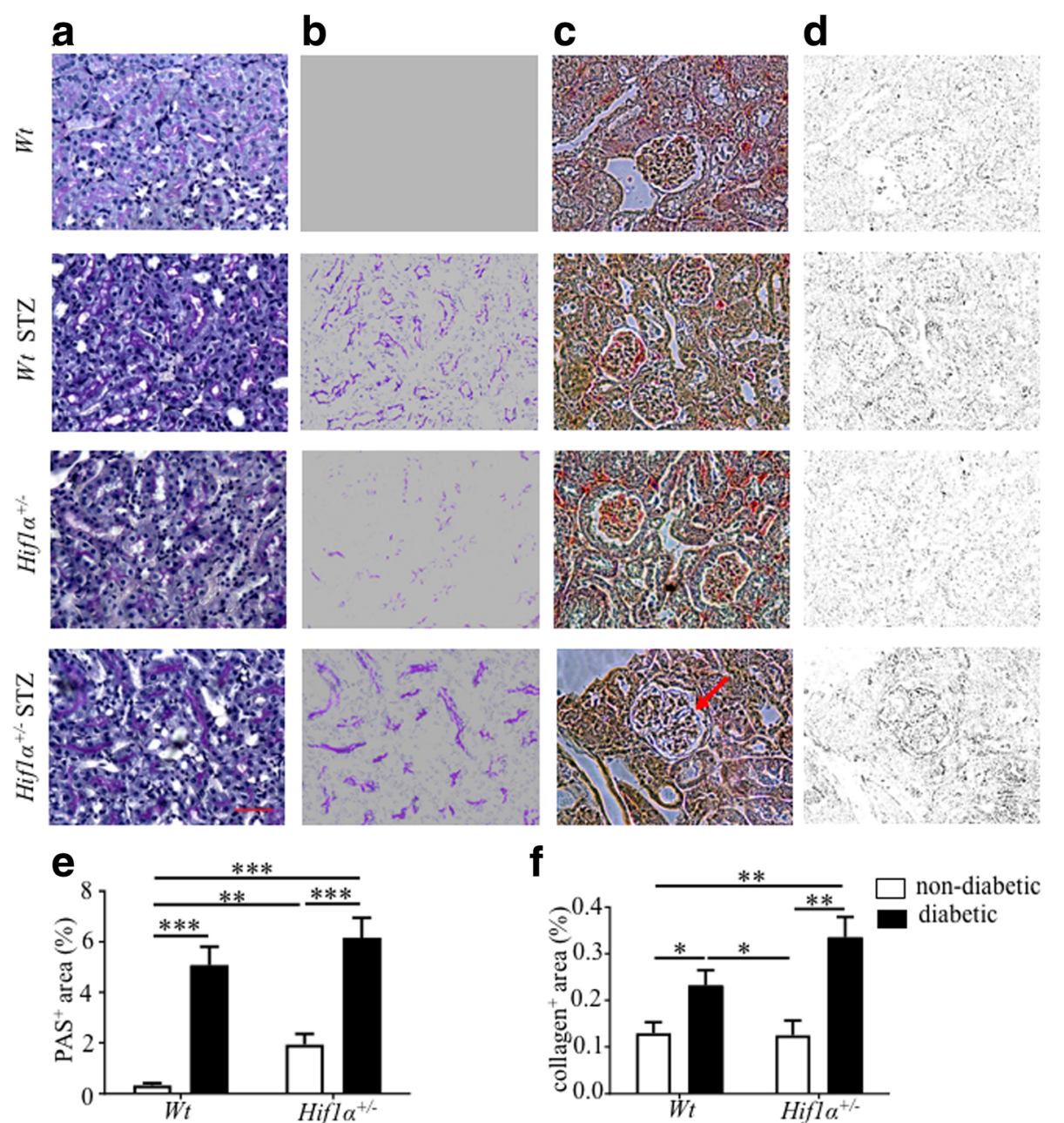

Fig. 2 PAS and trichrome-staining of the renal cortex in non-diabetic and diabetic Wt and Hifla ${ }^{+/-}$mice. a Representative PAS staining of $8 \mu m$ kidney sections showed advanced glycation end products in diabetic Wt (Wt STZ) and diabetic Hifla ${ }^{+/-}$(Hifla ${ }^{+/-}$STZ). The strongest positive staining was detected in the tubular part of the kidney section. b Delineated PAS ${ }^{+}$area in the kidney section using Adobe Photoshop. c Representative Masson's trichrome-staining of $8 \mu \mathrm{m}$ kidney sections showed increased fibrosis with increased collagen fibers in the renal cortex of diabetic kidneys. $\mathbf{d}$ Delineated collagen ${ }^{+}$area in the kidney section by ImageJ. e-f A relative quantification of staining was determined as a percentage of positive area in the field of view by ImageJ. Scale bar $100 \mu \mathrm{m}$. The values represent means \pm SEM ( $n=3$ sections/3 samples/group). Statistical significance differences were tested by two-way ANOVA (diabetes effect: PAS and trichrome $(P<0.0001)$; effect of genotype in PAS staining $(P=0.04))$. ${ }^{*}$ Significant differences by post hoc pairwise comparison, ${ }^{*} P<0.05,{ }^{* *} P<0.01$, ${ }^{* * *} P<0.0001$

Cx43 expression compared to non-diabetic Wt. Consistently, decreased protein levels of CX43 were detected in the renal cortex of diabetic Hifl $\alpha^{+/-}$mice, indicating impaired intercellular communication that may cause endothelial cell dysfunction and glomerular injury (Fig. 3b, c).

\section{Podocyte dysfunction in diabetic $\mathrm{Hifla}^{+/-}$mice}

Podocytes highly express vascular endothelial growth factor (VEGFA) and any small changes in VEGFA levels cause significant aberrations in glomerular structure [33]. We detected significantly higher VEGFA expression in the glomerulus of diabetic Hifl $\alpha^{+/-}$mice compared to diabetic Wt (Fig. 4a-d), indicating early deleterious changes in diabetic disease. Podocyte loss was also demonstrated by staining with WT1 (Fig. 4c), a nuclear marker of mature and fully functional podocytes [34]. The number of WT1 positive podocytes per glomerulus area was significantly decreased in diabetic $\mathrm{Hifl}^{+/-}$compared to diabetic Wt (Fig. 4e). Together with the increased expression Nphs2 (Fig. 3a), a marker for podocyte damage, our data thus indicate that Hifl $\alpha$ partial deficiency combined with diabetes accelerates podocyte loss and the inability to sustain the glomerular filtration barrier.

\section{Diabetes-induced changes associated with profibrotic processes and accumulation of extracellular matrix} Our gene expression profiling analyses showed significant changes in the expression of profibrotic markers induced 

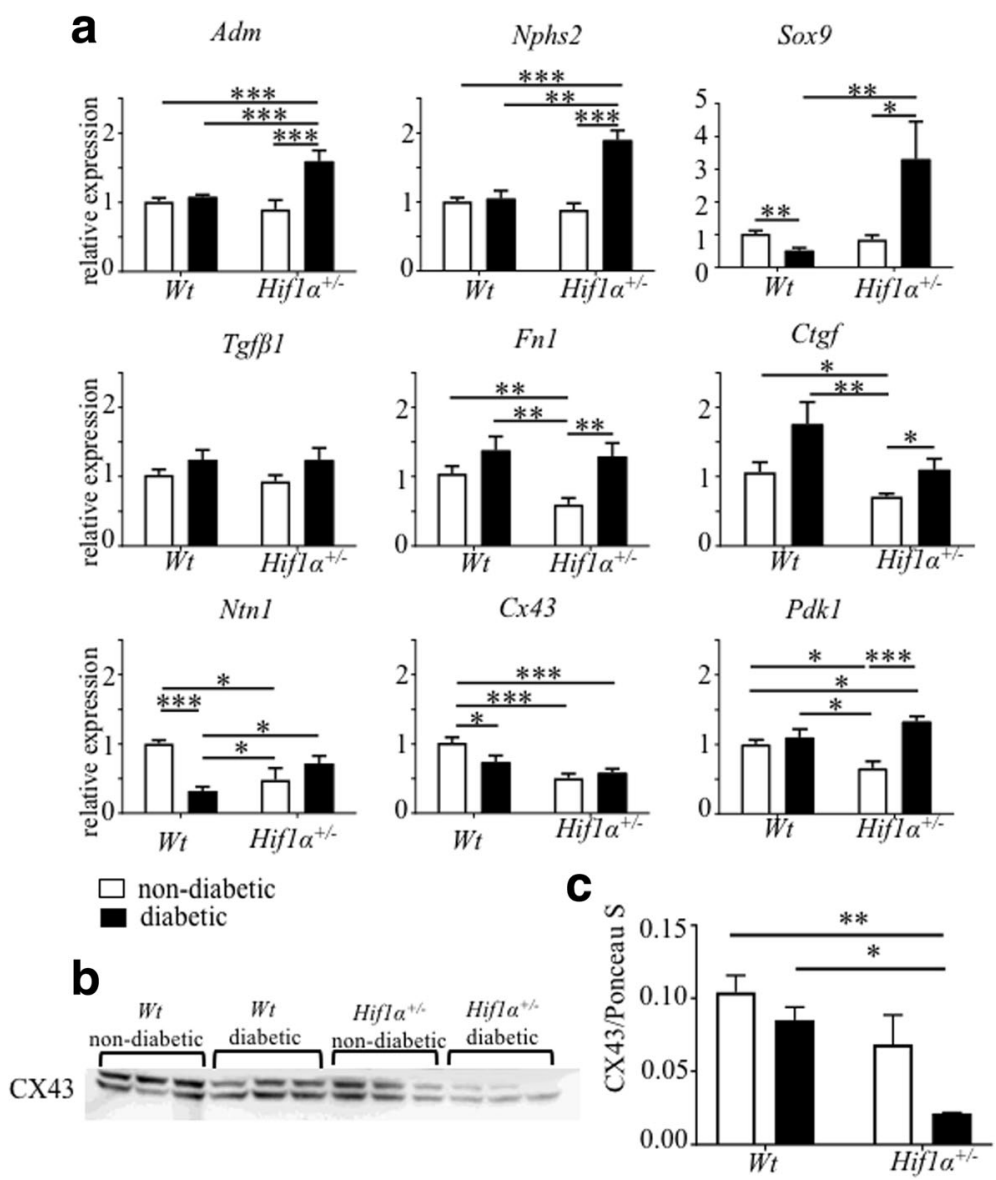

Fig. 3 Gene expression changes in the renal cortex of diabetic and non-diabetic Wt and Hifla ${ }^{+/-}$mice. a The relative gene expression changes were analyzed using RT-qPCR and quantified with $\Delta \Delta C T$ method. The values represent means \pm SEM ( $n=8$ samples/group). Statistical significance differences in normalized Ct values were tested by two-way ANOVA followed by post hoc pairwise comparison tests ${ }^{*} P<0.05$, ${ }^{*} P<0.01,{ }^{* * *} P<0.001$. b The renal cortex extracts were prepared and probed on Western blots with antibodies directed against connexin 43 (CX43; 43 kDa). Representative immunoblot for CX43 is shown. c Combined results obtained by densitometric evaluation of the Western blots of CX43 using cortical extracts from three mice per group. Ponceau S staining was used as the loading control. Data were analyzed by ImageJ software. Statistical significance differences were tested by two-way ANOVA followed by post hoc pairwise comparison tests ${ }^{*} P<0.05$, ${ }^{* *} P<0.01$. Abbreviations: adrenomedullin (Adm), podocin (Nphs2), SRY (Sex Determining Region Y)-Box 9 (Sox9)), transforming growth factor beta 1 (TgfB1), fibronectin 1 (Fn1), connective tissue growth factor (Ctgf), netrin (Ntn1), connexin 43 (CX43), and pyruvatdehydrogenase kinase1 (Pdk1)

by the diabetic milieu. We analyzed the expression of $\alpha$-SMA, an excellent prognostic indicator of renal fibrosis progression and marker of extracellular matrix accumulation [35]. The expression of $\alpha$-SMA was significantly increased in both diabetic Wt and Hifl $\alpha^{+/-}$ mice (Fig. 5a, b). The diabetic milieu triggers early tubular cell proliferation. Proximal tubule growth involves an early period of hyperplasia followed by a shift to hypertrophy [24]. Consistent with a hyperplasia phenotype in an early stage of DN, the number of mitotic cells found in tubular cells was increased in both diabetic Wt and Hifla ${ }^{+/-}$kidneys in comparison with non-diabetics (Fig. 5a, b). We did not detect any significant differences associated with the $\mathrm{Hifl}^{+/-}$ phenotype.

\section{Discussion}

Our partial deficiency Hif1 $\alpha$ model provides the first model that tests in vivo the function of HIF-1 $\alpha$ in the development and progression of diabetes-induced renal damage. Previous work has only provided indirect evidence for the role of HIF-1 $\alpha$, using a HIF-1 inhibitor [6] or HIF-1 activator [16]. Our data extend previous findings that HIF- $1 \alpha$ signaling is activated in the kidneys of experimental models with type I and type II diabetes and that it may be relevant to the development of $\mathrm{DN}$ $[4,5,12]$. We examined the role of HIF- $1 \alpha$ in the early stage of disease using the STZ-induced diabetic mouse model characterized by hyperglycemia (blood glucose levels $>13.9 \mathrm{mmol} / \mathrm{L}$ ) and insulinopenia. We found that Hifla partial deficiency significantly accelerated the 


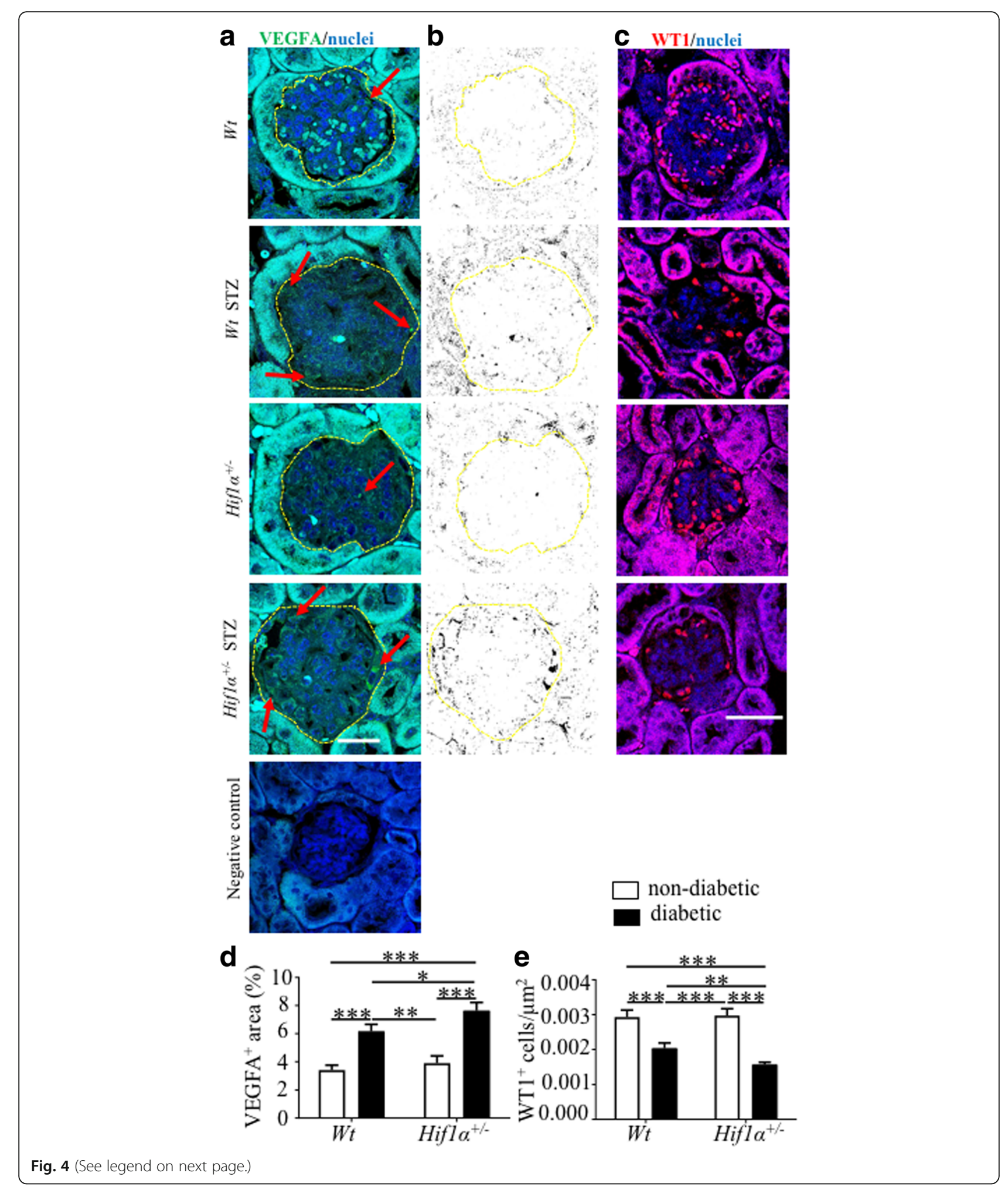




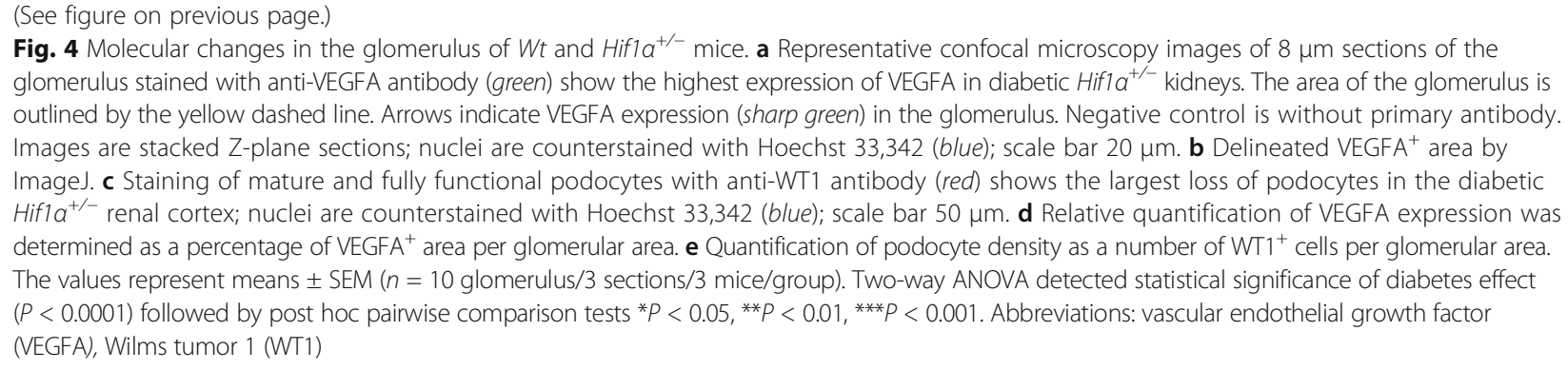

manifestation of pathological changes associated with the progression of DN. Changes in serum biochemical parameters associated with diabetic glomerular injury and progression of chronic kidney disease were more significant in diabetic $\mathrm{Hifl}^{+/-}$compared to diabetic Wt mice. The combination of Hifl $\alpha$ deficiency and diabetes resulted in an altered transcriptional expression profile of the renal cortex and decreased survival of podocytes.

Hypoxia represents an early and potentially initiating factor in the development and progression of chronic kidney diseases including DN [4, 36]. HIF-1 mediates hypoxia-induced cellular responses through the regulation of genes involved in cell metabolism, glucose utilization, angiogenesis, oxidative stress, apoptosis, and proliferation. However, the activation of HIF-1 in the diabetic kidney may be suboptimal despite profound renal hypoxia, as suggested by a large body of evidence showing that the diabetic milieu deregulates the HIF- $1 \alpha$ pathway [13-15]. In recent years, HIF-1 $\alpha$ genetic polymorphisms have emerged as potentially important determinants of disease severity and adverse outcomes $[37,38]$. Nonetheless, given the diversity of HIF-1 signaling, it remains controversial whether the activation of HIF-1 signaling exerts a beneficial or harmful role in the progression of renal diseases, particularly DN.

Persistent, chronic exposure to hypoxia is associated with structural tissue remodeling, such as renal fibrosis, inflammation, apoptosis and loss of microvasculature. HIF-1 signaling is an important protective physiological mechanism activated to counteract hypoxia and prevent renal damage (for review, see [39]). For example, the global inactivation of the Vhlh gene by the Cre-loxP system resulted in HIF- $1 \alpha$ and HIF- $2 \alpha$ stabilization and suppressed fibrogenesis in mice subjected to unilateral ureteral obstruction [40]. Other studies using pharmacological approaches for systemic HIF-1 activation demonstrated improved proteinuria and histological parameters in experimental chronic kidney disease models [41, 42]. In contrast, other studies have shown that sustained HIF-1 activation may have unfavorable effects. Genetic inactivation of the Vhlh gene in tubular epithelial cells resulted in constitutive HIF- $1 \alpha$ stabilization and accelerated renal fibrosis [43]. Similarly, the genetic ablation of Hifla in the renal proximal tubule inhibited tubulointerstitial fibrosis in the in vivo model of unilateral ureteral obstruction [44]. These data suggest that HIF-1 $\alpha$ may play different roles in the progression of chronic kidney diseases depending on the mode of activation, cell-type specific action, and local versus global HIF- $1 \alpha$ stabilization. Thus, these conflicting results reflect the complexity of the adaptive responses mediated by HIF-1.

Similar discrepancies have been reported regarding the role of HIF-1 in DN. An indirect approach using YC-1 [3-(5'-hydroxymethyl-2'-furyl)-1-benzyl indazole], a HIF-1 inhibitor, reduced glomerular hypertrophy and AGE in the type 1 diabetes mouse model [6]. In contrast, an induction of HIF- $1 \alpha$ by $\mathrm{CoCl}_{2}$ reduced proteinuria and histological markers of kidney injury in an obese type 2 diabetes model [16] and in STZ-induced DN in rats [3]. In conjunction with these studies, our data demonstrate that a partial Hifl $\alpha$ deficiency promotes the diabetes-induced kidney injury. Hifl $\alpha$ partial deficiency was associated with a reduced expression of HIF-1-targeted genes Pdk1, Ntn1, Ctgf, and Fn1. Serum glucose levels were significantly increased in $\mathrm{Hifl}^{+/-}$mice compared to Wt, implying systemic changes in glucose metabolism in association with Hifl $\alpha$ partial deletion, which may contribute to the enhanced pathogenesis. HIF-1, by regulating the expression of glucose transporter GLUT1 and glycolytic enzymes, affects glucose homeostasis, including the regulation of glucose-stimulated insulin secretion (GSIS) from the pancreatic beta-cells [45]. Targeted disruption of Hifl $\alpha$ in pancreatic beta-cells resulted in glucose intolerance, impaired GSIS, and beta-cell dysfunction [46]. Thus, the increased serum glucose levels in our diabetic $\mathrm{Hifl}^{+/-}$ mice were in accordance with the changes in beta-cell function and impaired glucose homeostasis.

These changes were accompanied by glomerular damage, as indicated by a significant loss of podocytes and increased expression of podocin, a marker for podocyte damage, in the diabetic $\mathrm{Hifl}^{+/-}$renal cortex. These results suggest that HIF- $1 \alpha$ functional impairment affected the survival of podocytes in the diabetes-exposed kidney. It is important to notice that systemic pharmacological approaches used in previous studies of $\mathrm{DN}[3,6,16]$ may produce HIF-1-independent effects and may also 


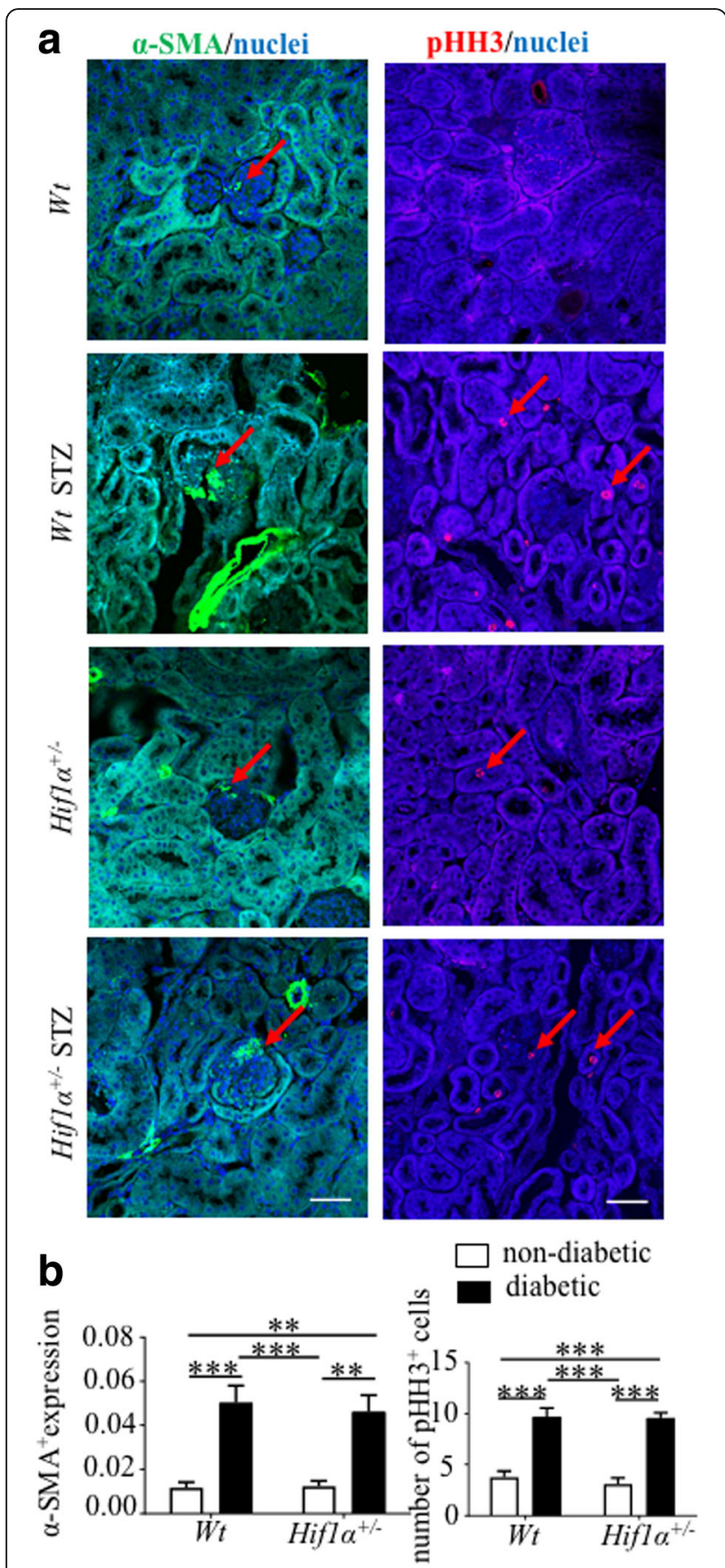

Fig. 5 Diabetes-induced changes in a-SMA and $\mathrm{pHH} 3$ expression in the kidney of Wt and Hifla ${ }^{+/-}$mice. a Confocal imaging of $8 \mu \mathrm{m}$ sections of the kidney stained with anti-a-SMA and anti-pHH3 antibodies. Images are stacked Z-plane sections; nuclei are counterstained with Hoechst 33,342 (blue); scale bars $50 \mu \mathrm{m}$. b Quantification of $\mathrm{a}-\mathrm{SMA}{ }^{+}$area was done per glomerular area (10 glomerulus/each section) and the positive $\mathrm{pHH}^{+}$staining was determined as a number of the positive nuclei in the field of view of the renal cortex. The values represent means \pm SEM ( $n=3$ sections/3mice/group). Statistical significance assessed by two-way ANOVA: diabetes effect in the expression of $\mathrm{pHH}$ and a-SMA $(P<0.0001)$. Post hoc pairwise comparison ${ }^{* *} P<0.01$, ${ }^{* *} P<0.001$. Abbreviations: alpha smooth muscle actin (a-SMA), phospho-histone $\mathrm{H} 3$ ( $\mathrm{pHH} 3)$ affect other tissues resulting in different responses in diabetes-exposed kidneys.

In response to injury, mesangial cells transdifferentiate and synthesize different extracellular matrix proteins, which is an important pathological event during glomerulosclerosis and the progression of DN. The increased expression of transcription factor SOX9 has been associated with changes in mesangial cells and expansion of the mesangial area in the progression of DN [28]. Additionally, the activation of SOX9 is critical for the early damage and repair response of injured renal tubule cells [47]. This repair response in the chronically active form may represent an additional mechanism triggering longterm pathological responses resulting in kidney damage. Not only HIF-1 mediates Sox9 expression, ERK1/2 signaling [48] or BMP4 [28] may also induce Sox9 expression. Furthermore, advanced glycation end products (AGEs) have been shown to induce Sox9 expression [28]. Thus, we can postulate that increased Sox9 expression in the diabetic $\mathrm{Hifl}^{+/-}$renal cortex may indicate a) an early transcriptional response to renal injury or/and b) regulatory compensatory response to Hifla deficiency and diabetic environment.

We found increased collagen accumulation in both diabetic Hifl $\alpha^{+/-}$and Wt mice. Correspondingly, the expression of markers of fibrosis and extracellular matrix accumulation, $T g f \beta 1$, fibronectin, Ctgf, and $\alpha$-SMA were increased in both diabetic Hifl $\alpha^{+/-}$and Wt mice. These results indicate that fibrosis in the diabetic kidney was not affected by the global reduction of Hifl $\alpha$, at least not in the early phase of diabetic exposure. In line with our observations are studies where the global Hifl $\alpha$ deletion using the Ubc-cre/ERT2 system did not affect collagen accumulation, although inflammation and renal injury were enhanced by Hifl $\alpha$ deletion in the model of unilateral ureteral obstruction [49].

VEGFA stimulates endothelial cell proliferation and has a key role in physiologic and pathologic angiogenesis in different tissues. In the kidney, VEGFA regulates glomerular permeability and maintenance of the glomerular tuft, and overall maintenance of kidney integrity [50]. VEGFA is tightly regulated as shown by glomerular-selective overexpression or deletion of VEGFA resulting in severe and early renal pathologies [33]. Renal diseases are frequently associated with impaired angiogenesis, capillary loss, and a reduction of VEGFA expression. In contrast, in diabetic nephropathy, renal VEGFA levels are elevated in experimental models as well as in diabetic patients [51-53] The upregulation of VEGFA has been proposed as a contributing mechanism to renal dysfunction during the early phase of diabetes $[53,54]$. Inhibition of VEGFA at the onset of diabetes abolished the associated diabetes-glomerular hyperfiltration, glomerular hypertrophy, and urinary albumin excretion in the type I 
diabetes model [53]. In our study, consistent with previously published data, VEGFA expression was significantly increased in the glomerulus of diabetic $H i f 1 \alpha^{+/-}$compared to the diabetic $W t$, indicating a faster progression of renal dysfunction in diabetes (Fig. 4). The cause of the upregulation of VEGFA in the diabetic kidney remains speculative; however, multiple factors may be implicated [53]. Renal dysfunction of diabetic $\mathrm{Hifl}^{+/-}$mice was further supported by the increased expression of $A d m$ in the diabetic $\mathrm{Hifl}^{+/-}$renal cortex. The upregulation of $\mathrm{Adm}$, which encodes a potent vasorelaxant peptide, is associated with glomerular hyperfiltration and dilatation of the glomerular capillaries in the acute phase of type 1 diabetes [55]. Notably, serum albumin levels were significantly decreased in diabetic $\mathrm{Hifl}^{+/-}$mice (Fig.1).

A limitation of our study is the global nature of the Hif1 $\alpha$ deletion. We are unable to determine which cell type or which combinations of cell types are contributing to the increased susceptibility of $\mathrm{Hifl}^{+/-}$mice to DN. The global deletion of Hifl $\alpha$ may affect other tissues and it may indirectly escalate pathological functional and structural changes in the kidney of $\mathrm{Hifl}^{+/-}$mutants. At the same time, our model reproduces the conditions of a global inhibition of HIF-1 signaling, such as in pharmacological targeted-HIF-1 inhibition.

\section{Conclusions}

Taken together, our studies point to a protective role of HIF-1 signaling in the early phase of adaptive responses to diabetic environment and that impaired HIF-1 signaling results in a faster progression of DN. Furthermore, our data suggest a potential role of Hifl $\alpha$ genetic variations in the manifestation of DN. Although the modulation of HIF-1 activity is a high-priority target for clinical therapies, our data accentuate the necessity of optimizing possible pharmacological inhibition of HIF-1 in therapeutic applications for the treatment of DN.

\section{Additional file}

Additional file 1: Table S1. The additional file lists primer sequences for genes analyzed by qPCR. (JPEG $122 \mathrm{~kb}$ )

\begin{abstract}
Abbreviations
Adm: Adrenomedullin; AGE: Advanced glycation end products; Ctgf: Connective tissue growth factor; Cx43: Connexin 43; DN: Diabetic nephropathy; Fn1: Fibronectin 1; GSIS: Glucose-stimulated insulin secretion; HIF-1: Hypoxia inducible factor 1; Nphs2: Podocin; Ntn1: Netrin; PAS: Periodic acid-Schiff staining; Pdk1: Pyruvatdehydrogenase kinase1; ROS: Reactive oxygen species; Sox9: SRY (Sex Determining Region Y)-Box 9;

STZ: Streptozotocin; Tgf $\beta 1$ : Transforming growth factor beta 1;

Vegfa: Vascular endothelial growth factor; Wt: Wild-type; Wt1: Wilms tumor 1 homolog; a-SMA: Alpha 2 smooth muscle actin
\end{abstract}

\section{Acknowledgements}

We thank A. Pavlinek for editing the manuscript. Serum analysis were done by the Czech Centre for Phenogenomics supported by LM2015040, LQ1604
(NPU II), by MEYS and CAS (RVO 68378050). We thank the Imaging Methods Core Facility at BIOCEV supported by the MEYS CR (LM2015062 Czech-Biolmaging).

\section{Funding}

This work was supported by the Czech Science Foundation (Grant Agreement No. 16-06825S to GP); by BIOCEV CZ.1.05/1.1.00/02.0109 from the ERDF; and AVOZ50520701 from the MEYS; by the Charles University in Prague (GA UK No. 228416 to $R C$ ).

\section{Availability of data and materials}

The datasets used and/or analyzed during the current study are available from the corresponding author on reasonable request.

\section{Authors' contributions}

All authors have read and approved the manuscript. G.P. conceived the study and takes responsibility for the integrity of the data. GP and RB co-wrote the manuscript. RC provided critical reading of the manuscript. RB and KN conducted animal study. RB and KN designed and performed $\mathrm{PPCR}$ analyses. RB performed Western blotting and confocal immunohistochemical analyses. RC designed and conducted histological and morphological analyses, and interpreted acquired data.

\section{Ethics approval and consent to participate}

This study was conducted in accordance with the Guide for the Care and Use of Laboratory Animals (NIH Publication No. 85-23, revised 1996). The experimental protocol was approved by the Animal Care and Use Committee of the Institute of Molecular Genetics, CAS. All applicable international, national, and/or institutional guidelines for the care and use of animals were followed. Al procedures performed in studies involving animals were in accordance with the ethical standards of the Institute of Molecular Genetics CAS at which the studies were conducted.

\section{Consent for publication}

Not applicable.

\section{Competing interests}

The authors declare that they have no competing interests.

\section{Publisher's Note}

Springer Nature remains neutral with regard to jurisdictional claims in published maps and institutional affiliations.

\section{Author details}

'Laboratory of Molecular Pathogenetics, Institute of Biotechnology CAS, BIOCEV, Center of Excellence, Prumyslova 595, Vestec 25242, Czechia.

${ }^{2}$ Faculty of Science, Charles University, Prague, Czechia.

Received: 1 January 2017 Accepted: 31 July 2017

Published online: 03 August 2017

\section{References}

1. Parving $\mathrm{HH}$. Blockade of the renin-angiotensin-aldosterone system and renal protection in diabetes mellitus. J Renin-Angiotensin-Aldosterone Syst. 2000;1(1):30-1.

2. Taft JL, Nolan CJ, Yeung SP, Hewitson TD, Martin FI. Clinical and histological correlations of decline in renal function in diabetic patients with proteinuria. Diabetes. 1994:43(8):1046-51

3. Nordquist L, Friederich-Persson M, Fasching A, Liss P, Shoji K, Nangaku M Hansell P, Palm F. Activation of hypoxia-inducible factors prevents diabetic nephropathy. J Am Soc Nephrol. 2015;26(2):328-38.

4. Rosenberger C, Khamaisi M, Abassi Z, Shilo V, Weksler-Zangen S, Goldfarb M, Shina A, Zibertrest F, Eckardt KU, Rosen S, et al. Adaptation to hypoxia in the diabetic rat kidney. Kidney Int. 2008;73(1):34-42.

5. Isoe T, Makino Y, Mizumoto K, Sakagami H, Fujita Y, Honjo J, Takiyama Y, Itoh $\mathrm{H}$, Haneda M. High glucose activates HIF-1-mediated signal transduction in glomerular mesangial cells through a carbohydrate response element binding protein. Kidney Int. 2010;78(1):48-59.

6. Nayak BK, Shanmugasundaram K, Friedrichs WE, Cavaglierii RC, Patel M, Barnes J, Block K. HIF-1 mediates renal fibrosis in OVE26 type 1 diabetic mice. Diabetes. 2016;65(5):1387-97. 
7. Semenza GL. Oxygen sensing, homeostasis, and disease. N Engl J Med 2011;365(6):537-47.

8. Li J, Bosch-Marce M, Nanayakkara A, Savransky V, Fried SK, Semenza GL, Polotsky W. Altered metabolic responses to intermitternt hypoxia in mice with partial deficiency of hypoxia-inducible factor 1 a. Physiol Genomics. 2006:25:450-7.

9. Bohuslavova R, Kolar F, Kuthanova L, Neckar J, Tichopad A, Pavlinkova G. Gene expression profiling of sex differences in HIF1-dependent adaptive cardiac responses to chronic hypoxia. J Appl Physiol. 2010;109(4):1195-202

10. Semenza GL. Hypoxia-inducible factor 1 and cardiovascular disease. Annu Rev Physiol. 2014;76:39-56.

11. Majmundar AJ, Wong WJ, Simon MC. Hypoxia-inducible factors and the response to hypoxic stress. Mol Cell. 2010;40(2):294-309.

12. Makino H, Miyamoto Y, Sawai K, Mori K, Mukoyama M, Nakao K, Yoshimasa $Y$, Suga S. Altered gene expression related to glomerulogenesis and podocyte structure in early diabetic nephropathy of $\mathrm{db} / \mathrm{db}$ mice and its restoration by pioglitazone. Diabetes. 2006;55(10):2747-56.

13. Catrina SB, Okamoto K, Pereira T, Brismar K, Poellinger L. Hyperglycemia regulates hypoxia-inducible factor-1alpha protein stability and function. Diabetes. 2004;53(12):3226-32.

14. Thangarajah H, Yao D, Chang El, Shi Y, Jazayeri L, Vial IN, Galiano RD, Du $X L$, Grogan R, Galvez MG, et al. The molecular basis for impaired hypoxia-induced VEGF expression in diabetic tissues. Proc Natl Acad Sci U S A. 2009;106(32):13505-10.

15. Bento CF, Pereira P. Regulation of hypoxia-inducible factor 1 and the loss of the cellular response to hypoxia in diabetes. Diabetologia. 2011;54(8):1946-56.

16. Ohtomo S, Nangaku M, Izuhara Y, Takizawa S, Strihou C, Miyata T. Cobalt ameliorates renal injury in an obese, hypertensive type 2 diabetes rat model. Nephrol Dial Transplant. 2008;23(4):1166-72.

17. Salbaum JM, Kruger C, Zhang X, Delahaye NA, Pavlinkova G, Burk DH, Kappen C. Altered gene expression and spongiotrophoblast differentiation in placenta from a mouse model of diabetes in pregnancy. Diabetologia. 2011;54(7):1909-20.

18. Bohuslavova R, Kolar F, Sedmera D, Skvorova L, Papousek F, Neckar J, Pavlinkova G. Partial deficiency of HIF-1alpha stimulates pathological cardiac changes in streptozotocin-induced diabetic mice. BMC Endocr Disord. 2014;14(1):11.

19. Iyer NV, Kotch LE, Agani F, Leung SW, Laughner E, Wenger RH, Gassmann M, Gearhart JD, Lawler AM, Yu AY, et al. Cellular and developmental control of O2 homeostasis by hypoxia-inducible factor 1 alpha. Genes Dev. 1998; 12(2):149-62.

20. Peng YJ, Yuan G, Ramakrishnan D, Sharma SD, Bosch-Marce M, Kumar GK, Semenza GL, Prabhakar NR. Heterozygous HIF-1alpha deficiency impairs carotid body-mediated systemic responses and reactive oxygen species generation in mice exposed to intermittent hypoxia. J Physiol. 2006;577(Pt 2):705-16.

21. Bosch-Marce M, Okuyama H, Wesley JB, Sarkar K, Kimura H, Liu YV, Zhang H, Strazza M, Rey S, Savino L, et al. Effects of aging and hypoxia-inducible factor-1 activity on angiogenic cell mobilization and recovery of perfusion after limb ischemia. Circ Res. 2007;101(12):1310-8.

22. Bohuslavova R, Skvorova L, Sedmera D, Semenza GL, Pavlinkova G. Increased susceptibility of HIF-1alpha heterozygous-null mice to cardiovascular malformations associated with maternal diabetes. J Mol Cell Cardiol. 2013;60:129-41.

23. Breyer MD, Bottinger E, Brosius FC 3rd, Coffman TM, Harris RC, Heilig CW, Sharma K, Amdcc. Mouse models of diabetic nephropathy. J Am Soc Nephrol. 2005;16(1):27-45.

24. Huang HC, Preisig PA. G1 kinases and transforming growth factor-beta signaling are associated with a growth pattern switch in diabetes-induced renal growth. Kidney Int. 2000;58(1):162-72.

25. Perticone M, Maio R, Sciacqua A, Cimellaro A, Andreucci M, Tripepi G, Zoccali C, Sesti G, Perticone F. Serum phosphorus levels are associated with endothelial dysfunction in hypertensive patients. Nutr Metab Cardiovasc Dis. 2016;26(8):683-8.

26. Soulis T, Thallas V, Youssef $S$, Gilbert RE, McWilliam BG, Murray-McIntosh RP, Cooper ME. Advanced glycation end products and their receptors colocalise in rat organs susceptible to diabetic microvascular injury. Diabetologia. 1997;40(6):619-28.

27. Tervaert TW, Mooyaart AL, Amann K, Cohen AH, Cook HT, Drachenberg CB, Ferrario F, Fogo $A B$, Haas $M$, de Heer $E$, et al. Pathologic classification of diabetic nephropathy. J Am Soc Nephrol. 2010;21(4):556-63.
28. Kishi S, Abe H, Akiyama H, Tominaga T, Murakami T, Mima A, Nagai K, Kishi F, Matsuura M, Matsubara T, et al. SOX9 protein induces a chondrogenic phenotype of mesangial cells and contributes to advanced diabetic nephropathy. J Biol Chem. 2011;286(37):32162-9.

29. Bottinger EP. TGF-beta in renal injury and disease. Semin Nephrol. 2007; 27(3):309-20.

30. Rosenberger P, Schwab JM, Mirakaj V, Masekowsky E, Mager A, MoroteGarcia JC, Unertl K, Eltzschig HK. Hypoxia-inducible factor-dependent induction of netrin-1 dampens inflammation caused by hypoxia. Nat Immunol. 2009;10(2):195-202.

31. Tittarelli A, Janji B, Van Moer K, Noman MZ, Chouaib S. The selective degradation of synaptic connexin 43 protein by hypoxia-induced autophagy impairs natural killer cell-mediated tumor cell killing. J Biol Chem. 2015;290(39):23670-9.

32. Sato T, Haimovici R, Kao R, Li AF, Roy S. Downregulation of connexin 43 expression by high glucose reduces gap junction activity in microvascular endothelial cells. Diabetes. 2002:51(5):1565-71.

33. Eremina V, Sood M, Haigh J, Nagy A, Lajoie G, Ferrara N, Gerber HP, Kikkawa $Y$, Miner JH, Quaggin SE. Glomerular-specific alterations of VEGF-A expression lead to distinct congenital and acquired renal diseases. I Clin Invest. 2003;111(5):707-16.

34. Guo JK, Menke AL, Gubler MC, Clarke AR, Harrison D, Hammes A, Hastie ND, Schedl A. WT1 is a key regulator of podocyte function: reduced expression levels cause crescentic glomerulonephritis and mesangial sclerosis. Hum Mol Genet. 2002;11(6):651-9.

35. Essawy M, Soylemezoglu O, Muchaneta-Kubara EC, Shortland J, Brown CB, el Nahas AM. Myofibroblasts and the progression of diabetic nephropathy. Nephrol Dial Transplant. 1997;12(1):43-50.

36. Palm F, Hansell $P$, Ronquist $G$, Waldenstrom A, Liss P, Carlsson PO. Polyol-pathway-dependent disturbances in renal medullary metabolism in experimental insulin-deficient diabetes mellitus in rats. Diabetologia. 2004:47(7):1223-31.

37. Kolyada AY, Tighiouart $H$, Perianayagam MC, Liangos $\mathrm{O}$, Madias NE, Jaber $\mathrm{BL}$. A genetic variant of hypoxia-inducible factor-1alpha is associated with adverse outcomes in acute kidney injury. Kidney Int. 2009;75(12):1322-9.

38. Gu HF, Zheng X, Abu Seman N, Gu T, Botusan IR, Sunkari VG, Lokman EF, Brismar K, Catrina SB. Impact of the hypoxia-inducible factor-1 alpha (HIF1A) Pro582Ser polymorphism on diabetes nephropathy. Diabetes Care. 2013;36(2):415-21.

39. Haase VH. Hypoxia-inducible factors in the kidney. Am J Physiol Renal Physiol. 2006;291 (2):F271-81.

40. Brukamp K, Jim B, Moeller MJ, Haase VH. Hypoxia and podocyte-specific Vhlh deletion confer risk of glomerular disease. Am J Physiol Renal Physiol. 2007:293(4):F1397-407.

41. Song YR, You SJ, Lee YM, Chin HJ, Chae DW, Oh YK, Joo KW, Han JS, Na KY. Activation of hypoxia-inducible factor attenuates renal injury in rat remnant kidney. Nephrol Dial Transplant. 2010;25(1):77-85.

42. Deng A, Arndt MA, Satriano J, Singh P, Rieg T, Thomson S, Tang T, Blantz RC. Renal protection in chronic kidney disease: hypoxia-inducible factor activation vs. angiotensin II blockade. Am J Physiol Renal Physiol. 2010; 299(6):F1365-73.

43. Kimura K, Iwano M, Higgins DF, Yamaguchi Y, Nakatani K, Harada K, Kubo A, Akai Y, Rankin EB, Neilson EG, et al. Stable expression of HIF-1alpha in tubular epithelial cells promotes interstitial fibrosis. Am J Physiol Renal Physiol. 2008;295(4):F1023-9.

44. Higgins DF, Kimura K, Bernhardt WM, Shrimanker N, Akai Y, Hohenstein B, Saito Y, Johnson RS, Kretzler M, Cohen CD, et al. Hypoxia promotes fibrogenesis in vivo via HIF-1 stimulation of epithelial-to-mesenchymal transition. J Clin Invest. 2007;117(12):3810-20.

45. Cantley J, Selman C, Shukla D, Abramov AY, Forstreuter F, Esteban MA, Claret M, Lingard SJ, Clements M, Harten SK, et al. Deletion of the von Hippel-Lindau gene in pancreatic beta cells impairs glucose homeostasis in mice. J Clin Invest. 2009;119(1):125-35.

46. Cheng K, Ho K, Stokes R, Scott C, Lau SM, Hawthorne WJ, O'Connell PJ, Loudovaris T, Kay TW, Kulkarni RN, et al. Hypoxia-inducible factor-1alpha regulates beta cell function in mouse and human islets. J Clin Invest. 2010;120(6):2171-83.

47. Kumar S, Liu J, Pang P, Krautzberger AM, Reginensi A, Akiyama H, Schedl A, Humphreys BD, McMahon AP. Sox9 activation highlights a cellular pathway of renal repair in the acutely injured mammalian kidney. Cell Rep. 2015; 12(8):1325-38. 
48. Ling S, Chang X, Schultz L, Lee TK, Chaux A, Marchionni L, Netto GJ, Sidransky D, Berman DM. An EGFR-ERK-SOX9 signaling cascade links urothelial development and regeneration to cancer. Cancer Res. 2011; 71(11):3812-21.

49. Kobayashi H, Gilbert V, Liu Q, Kapitsinou PP, Unger TL, Rha J, Rivella S, Schlondorff D, Haase VH. Myeloid cell-derived hypoxia-inducible factor attenuates inflammation in unilateral ureteral obstruction-induced kidney injury. J Immunol. 2012;188(10):5106-15.

50. Schrijvers BF, Flyvbjerg A, De Vriese AS. The role of vascular endothelial growth factor (VEGF) in renal pathophysiology. Kidney Int. 2004;65(6):2003-17.

51. Cooper ME, Vranes D, Youssef S, Stacker SA, Cox AJ, Rizkalla B, Casley DJ, Bach LA, Kelly DJ, Gilbert RE. Increased renal expression of vascular endothelial growth factor (VEGF) and its receptor VEGFR-2 in experimental diabetes. Diabetes. 1999:48(11):2229-39.

52. Nakagawa T. Uncoupling of the VEGF-endothelial nitric oxide axis in diabetic nephropathy: an explanation for the paradoxical effects of VEGF in renal disease. Am J Physiol Renal Physiol. 2007;292(6):F1665-72.

53. de Vriese AS, Tilton RG, Elger M, Stephan CC, Kriz W, Lameire NH. Antibodies against vascular endothelial growth factor improve early renal dysfunction in experimental diabetes. J Am Soc Nephrol. 2001;12(5):993-1000.

54. Flyvbjerg A, Dagnaes-Hansen F, De Vriese AS, Schrijvers BF, Tilton RG, Rasch R. Amelioration of long-term renal changes in obese type 2 diabetic mice by a neutralizing vascular endothelial growth factor antibody. Diabetes. 2002;51(10):3090-4.

55. Hiragushi K, Wada J, Eguchi J, Matsuoka T, Yasuhara A, Hashimoto I, Yamashita T, Hida K, Nakamura Y, Shikata K, et al. The role of adrenomedullin and receptors in glomerular hyperfiltration in streptozotocin-induced diabetic rats. Kidney Int. 2004;65(2):540-50.

\section{Submit your next manuscript to BioMed Central and we will help you at every step:}

- We accept pre-submission inquiries

- Our selector tool helps you to find the most relevant journal

- We provide round the clock customer support

- Convenient online submission

- Thorough peer review

- Inclusion in PubMed and all major indexing services

- Maximum visibility for your research

Submit your manuscript at www.biomedcentral.com/submit

C) Biomed Central 